\title{
Formação de especialistas em Medicina de Família e Comunidade no Brasil: dilemas e perspectivas
}

\author{
Training of specialists in Family and Community Medicine in Brazil: dilemmas and perspectives \\ Formación de especialistas en Medicina Familiar y Comunitaria en Brasil: dilemas y perspectivas \\ Maria Inez Padula Anderson ${ }^{1}$, Ricardo Donato Rodrigues ${ }^{2}$
}

A formação de especialistas no âmbito da Atenção Primária à Saúde (APS), área privilegiada de atuação do Médico de Família e Comunidade (MFC), tem suscitado polêmicas no Brasil desde1976, quando foram criados os três programas pioneiros de Residência Médica (PRM) no país.

Questionava-se, então, a necessidade de se instituir programas de pós-graduação neste âmbito. Os defensores dessa tese confundiam APS com atenção simplificada, voltada para o atendimento de problemas de saúde igualmente simples.

Esta concepção reducionista não faz justiça à complexidade das questões de saúde que se apresentam de APS, cujas principais atribuições envolvem: prestar assistência adequada e resolutiva aos problemas de saúde mais prevalentes de uma população adscrita; prevenir a ocorrência de doenças evitáveis; retardar a instalação de agravos crônicos e a ocorrência de complicações precoces no curso das doenças e promover e preservar a saúde de pessoas, suas famílias e respectivas comunidades.

Para tanto, os profissionais devem ter capacitação específica e elevada qualificação técnica, inclusive para lançar mão de outros saberes e práticas que escapam ao domínio do paradigma anátomo-clínico, ainda hegemônico. Isto é, o especialista em MFC deve desenvolver competências que não estão situadas no plano da racionalidade biotecnológica que privilegia a dimensão fisiopatológica das doenças.

No âmbito da APS, é fundamental desenvolver conhecimentos, habilidades e atitudes que capacitem o MFC para abordar as pessoas e seus processos de saúde-adoecimento enquanto fenômenos complexos, com sentidos e significados, condicionados pelo entrelaçamento de fatores de diferentes dimensões. Ou seja, torna-se necessário desenvolver competências centradas em nova racionalidade, reconhecidas como o paradigma da integralidade biopsicossocial.

Como desenvolver, de forma eficaz, tais competências em cursos de especialização que são, basicamente, centrados em atividades teóricas e privilegiam os aspectos cognitivos?

Vale lembrar que os PRM devem disponibilizar mais de $80 \%$ da sua carga horária em treinamento em serviço, sob a supervisão de especialistas. Este processo de ensino-aprendizagem, junto a pares mais experientes, permite o desenvolvimento de habilidades instrumentais e atitudinais não passíveis de serem desenvolvidas em cursos de pós-graduação de outra natureza.

Além disso, os PRM, contam uma carga horária bastante alargada, cerca de 5.500 horas quando, na grande maioria das vezes, as outras formas de especialização não chegam 10 $\%$ deste montante.

Não é por outra razão que os PRM são considerados $p a$ drão-ouro na formação de médicos especialistas. No plano da APS e da MFC esta estratégia parece ser ainda mais relevante se for levado em conta o desafio de formar profissionais que, além das atividades assistenciais, deverão ocupar espaços, que precisam ser desbloqueados no seio das instituições de ensino com vista ao desenvolvimento progressivo de atividades docentes e de pesquisa. 
Importa realçar ainda que os PRM - cujos conteúdos programáticos e atividades teóricas são elaborados em parceria com as sociedades de especialidade - são regulamentados por lei e regidos por resoluções específicas da Comissão Nacional de Residência Médica, vinculada ao Ministério da Educação. Esta Comissão, através das subcomissões estaduais, implementa um processo de trabalho que envolve a certificação e a avaliação periódica dos PRM, buscando seu aperfeiçoamento longitudinal.

Isto não ocorre com os cursos de especialização, que em relação a este aspecto revelam, no Brasil, um agravante adicional: considerando que as áreas de atuação e os atributos específicos da MFC são ainda pouco (re)conhecidos, os cursos de especialização tendem a desenvolver conteúdos mais relacionados à área de saúde coletiva, deixando de aprofundar as especificidades clínicas da especialidade.

Tendo em vista estas considerações, a centralidade da formação de especialistas em Medicina de Família e Comunidade através de cursos de especialização, que não a residência médica, deve ser entendida, no Brasil, como uma estratégia de caráter transitório, também usada em outros países que implementaram a APS de forma mais acelerada, como no nosso país.

Nesta situação, o propósito é capacitar médicos, sem formação específica, que se encontram em atividades assistenciais na APS. Este recurso deve existir até que as políticas públicas nos campos da saúde e da educação venham apoiar decisivamente os programas de residência em MFC. Isto inclui a adoção de estratégias com o propósito de aumentar a competitividade dos PRMFC. Entre elas, a valorização da bolsa da residência em MFC, face à remuneração ofereci- da aos médicos da SF. Também será estratégico incluir o PRMFC no grupo das especialidades básicas que servem de acesso para outros PRM. As vantagens superariam as desvantagens, propiciando uma oportunidade de adesão à MFC por profissionais que, de outra forma poderiam ocupar, transitoriamente, postos de trabalho na SF até surgir oportunidade para seguir outro caminho profissional.

Por fim, vale lembrar que, para além da modalidade e qualificação dos programas de pós-graduação, será a organização de estratégias de desenvolvimento profissional contínuo que permitirá a implantação de processos consistentes para a manutenção e o aperfeiçoamento das competências dos especialistas e o incremento da qualidade dos serviços prestados à população ao longo do tempo.

\section{Referências}

1. Anderson MIP, Rodrigues RD. Formação em Medicina de Família e Comunidade. Cadernos ABEM. 2008 Out; 4:30-7.

2. Anderson MIP, Castro Filho ED, Rodrigues RD, Dalla MDB, Bourget MMM. Bases para expansão e desenvolvimento adequado de programas de Residência em Medicina de Família e Comunidade. Rev bras med fam comunidade. 2007 Out-Dez; 3(11):180-98.

3. Castro Filho ED, Gusso GDF, Demarzo MMP et al. A especialização em MFC e o desafio da qualificação médica para a Estratégia Saúde da Família: proposta de especialização em larga escala, via educação a distância. Rev bras med fam comunidade. 2007 Out-Dez; 3(11):199-209.

4. Rodrigues RD. Programa de Residência em Medicina de Família e Comunidade da UERJ: uma perspectiva histórica. Rev bras med fam comunidade 2007 Out-Dez; 3(11):149-56.

5. Rodrigues RD. Notas sobre um programa de residência em ambulatório. In: Anais do XXV Congresso Brasileiro de Homeopatia; 2000 Set; Rio de Janeiro (RJ). Rio de Janeiro (RJ): Sociedade Brasileira de Homeopatia; 200: 201-4. 